\title{
The Effect of Intellectual Transformation for Postmodernism on Structure Plans in Iraq
}

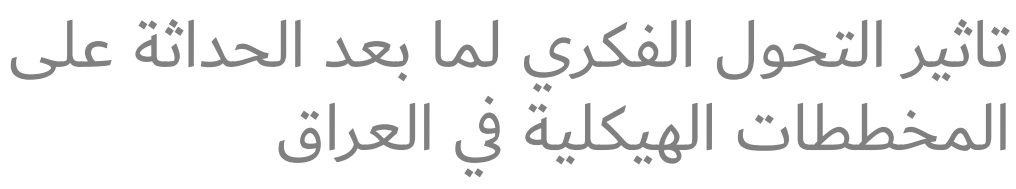

Ammar Khalil Ebraheem, Adil Hasan Jasim, and Mustafa Abdul Jalil Ebraheem

عمار خليل ابراهيم وعادل حسن جاسم ومصطفى عبد الجليل ابراهيم

Urban and Regional Planning Center for Postgraduate/ Baghdad University/Baghdad/Iraq

مركز التخطيط الحضري والاقليمي للدراسات العليا/ جامعة بغداد، بغداد/العراق

Corresponding Author: Ammar Khalil Ebraheem powderammer@yahoo.com

Received: 28 December 2017 Accepted: 2 February 2018

Published: 1 May 2018

Publishing services provided by Knowledge

(c) Ammar Khalil Ebraheem et al. This article is distributed under the terms of the Creative Commons Attribution License, which permits unrestricted use and redistribution provided that the original author and source are credited.

Selection and Peer-review under the responsibility of the Urban Planning Iraq Conference Committee.

\section{Abstract}

The intellectual transformations that followed the Second World War sought to find radical solutions to the challenges faced by the world city in the reconstruction process and how to transform the spatial dimension of these cities into a productive component of production rather than a challenge to the weak potential of the spatial plan. The intellectual movement known as postmodernism, affecting on all the concepts at this stage as an intellectual reaction to what the global system of challenges of capitalism and its effects on the restriction of building the spatial dimension, both within cities or outside it, which included the basic concepts that dealt with the spatial plan and what the principles according to the spatial dimension, research, trying to detect the effects of this movement and its relationship to dimension and strategic thinking to develop structural plans in Iraq.

كانت التحولات الفكرية التي تلت الحرب العالمية الثانية تسعى لايجاد حلول جائل الدذرية لما تواجهه المدينة

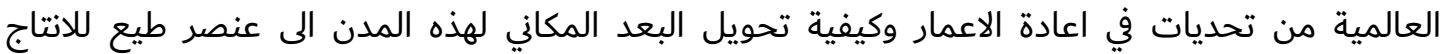

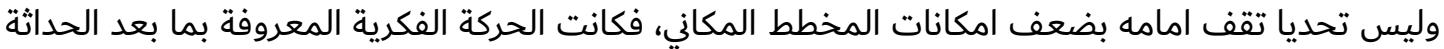

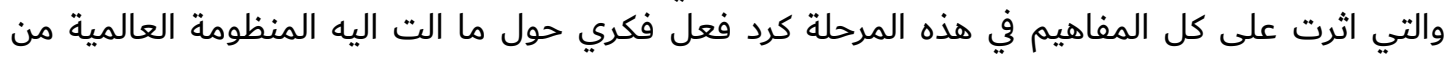

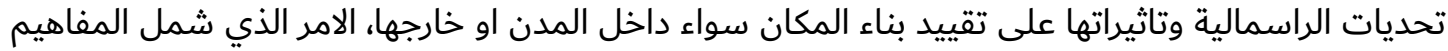

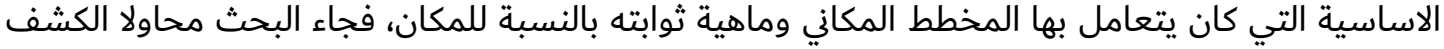

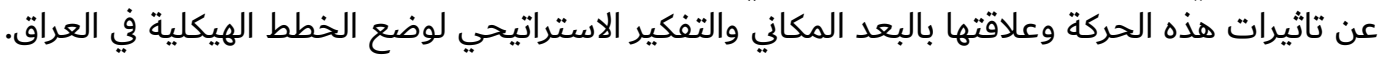

Keywords: postmodern, structure plan, spatial dimension, strategic plan.

الكلمات المفتاحية: مابعد الحداثة, خطة هيكلية, البعد المكاني, خطة استراتيجية

\section{S OPEN ACCESS}


إن إعداد الخطط الهيكلية يعد من المهمات الحديثة التي بدأت الحاجة إليها مؤخراً، ولكن لم تعنى بالأهمية

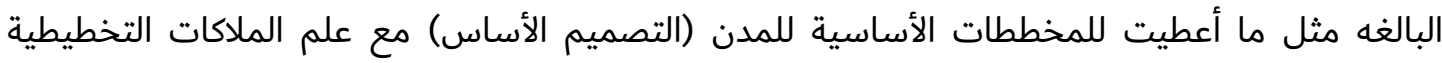
بان المخططات الهيكلية هي الرافد المهم للمخططات الأساسية و الاستراتيجية والتنموية لما تتضمن من

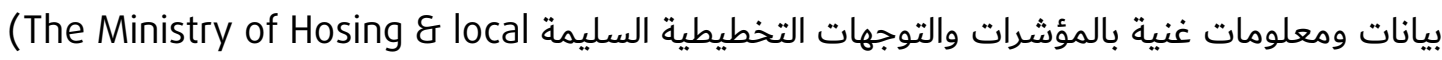
.Govermentm, 1965, P17) فكانت المشكلة البحثية هي في كيفية التنظيم المكاني وفق المفاهم الكلاسيكية التي تركز على البعد

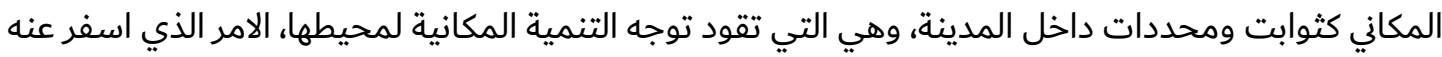

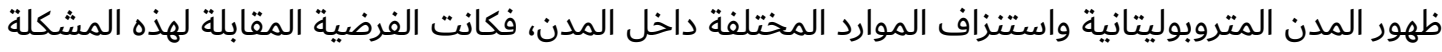

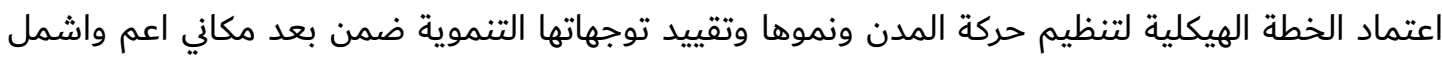
يضمن تحقيق الموازنة المجتمعية، وكنتيجة مباشرة لتغيرات الفكرية التي حدثت بعد الحبة الحرب العالمية المباد الثانية.

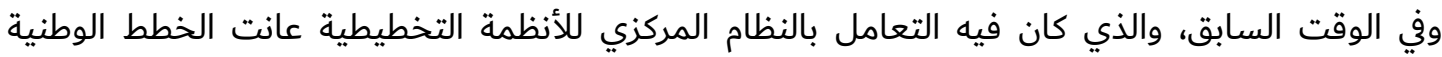

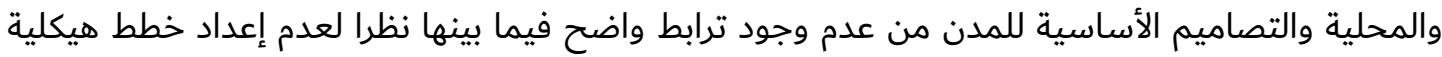

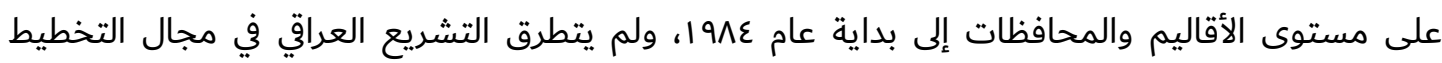

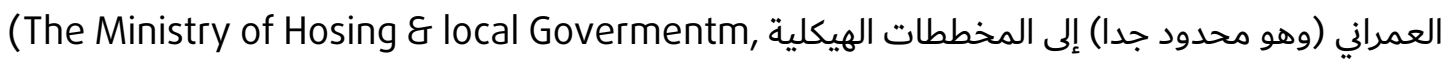

1965, p18)

\section{التاثيرات الفكرية لمرحلة ما بعد الحداثة والتخطيط}

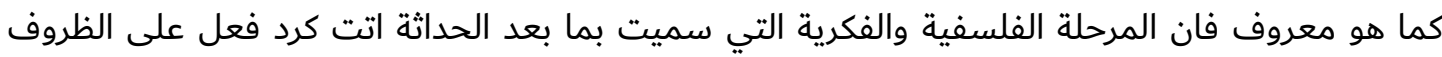

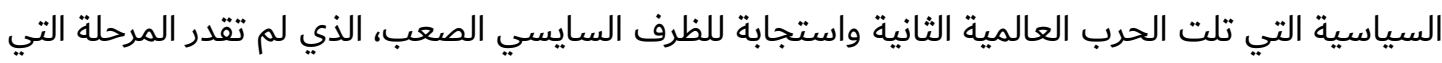
سبقتها وهي الحداثة على تلبية متطلباته الفكرية والتوجهات التي تمكن من بناء منظومة تستطيع النهوض بالعالم.

بنيت مرحلة الحداثة على ركائز من اهمها بان المعرفة هي ناتج تركز معرفي مجتمعي، بذلك فان الحقيقة

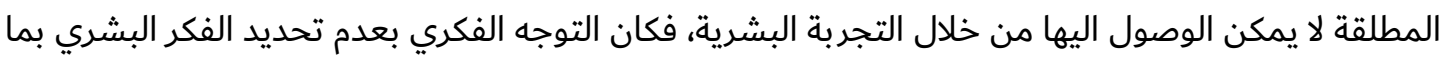
يعرف بالثوابت المطلقة، (Arvanitis, 2008, p106).

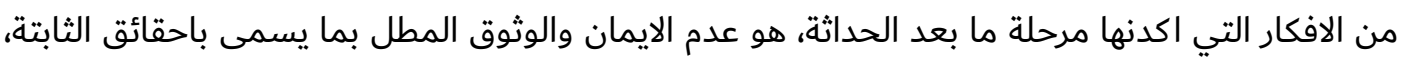

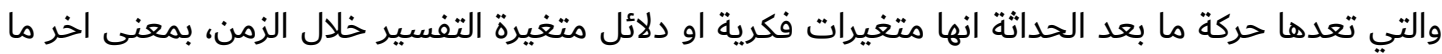
نتقبله اليوم وندافع عنه قد يكون تعاملنا معه العكس غدا، مندات (Navickas, 2011, P4). لذلك فان هذا الفكر حدد تعامل المخطط مع التخطيط المكاني من خلال الاعتماد على الرؤية والخبرة

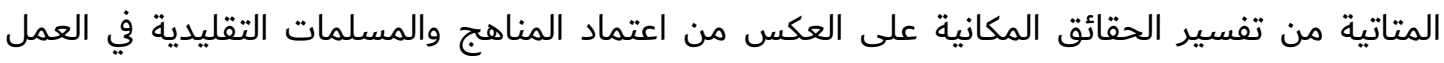

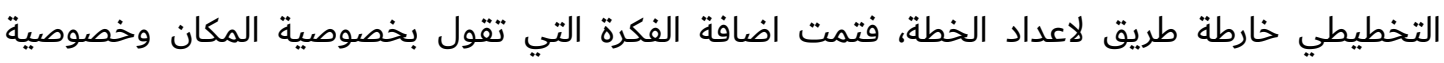

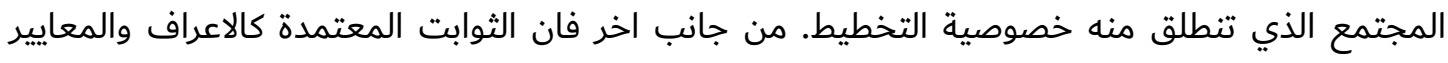

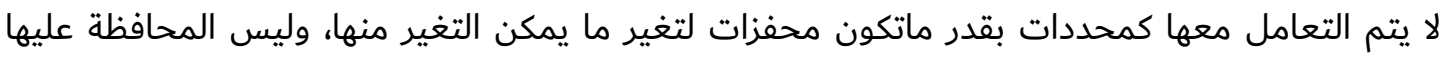

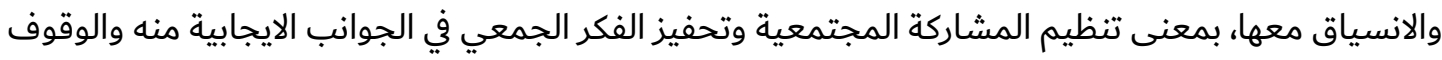


(Arvanitis, 2008, بالضد من هذا الفكر الجمعي ومحاولة ترويضه للافضل من خلال مراحل بناء الخطة،

وكانت مفاهيم الديمقراطية والمشاركة الجماهيرية في تحديد مصيرها واتخاذ قرارها من اهم الافكار التي نادت بها هذه المرحلة لكونها تسعى لاكساب الانظمة التي تدير المجتمعات الى الشرعية والمقبولية، فكان

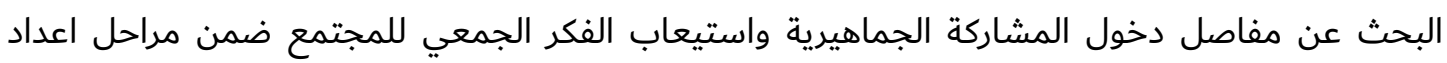

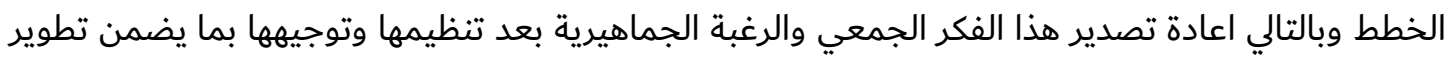
المجتمع نحو اعراف افضل من خلال الخطط المكانية لتوزيع الموارد والفعاليات، (Navickas, 2011, P2).

\section{ا. التجربة العراقية في إعداد المخططات الهيكلية}

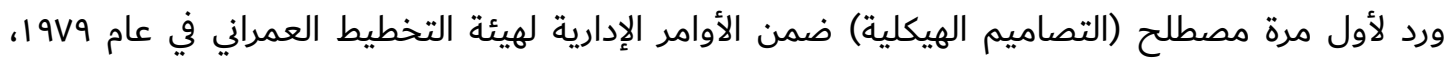
لتوصيف الملاك الفني والهندسي الذي سيعمل ضمن التصاميم الهيكلية في دوائر هيئة التخطيط العمراني

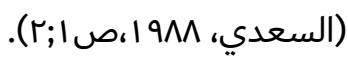

وقد عرف التصميم الهيكلي الأساس على مستوى المحافظة بأنه: التصميم الأساس للمحافظة، لتحديد استعمالات الأرض بصورة عامة ضمن المحافظة بما يضمن تنميتها وتطويرها اقتصاديا واجتماعيا وعمرانياً، ضمن الإطار الحالي لخطة الدولة في عملية التنمية الإقليمية. كما اوضح أن ذلك يتم عن طريق دراسة المعلومات المتوافرة عن كل محافظة، وتحليلها، ومقارنة

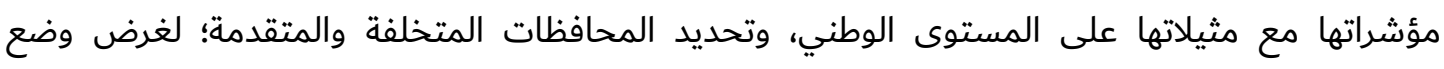

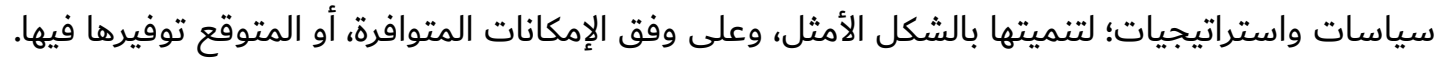

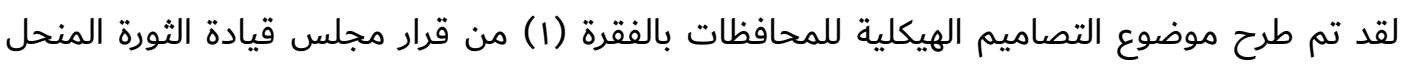

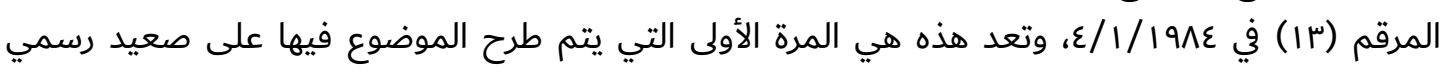

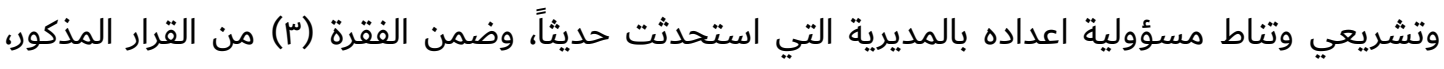

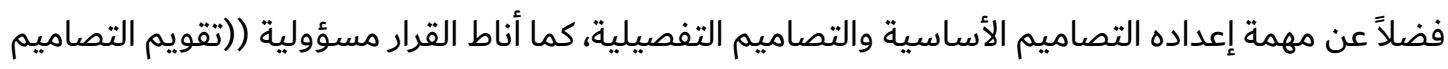
الهيكلية للمحافظات ضمن الإستراتيجية العامة للتنمية الاقليمية، وعلى وفق مؤشرات خطة التنمية الوطنية))، بهيئة التخطيط الإقليمي في هيئة التخطيط. ونتيجة لعدم وضوح تعريف المخطط الهيكلي، أو التصميم الأساس على المستوى التشريعي والتنفيذي التئي

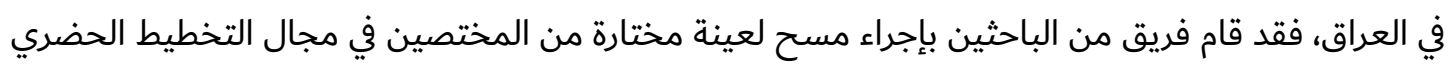

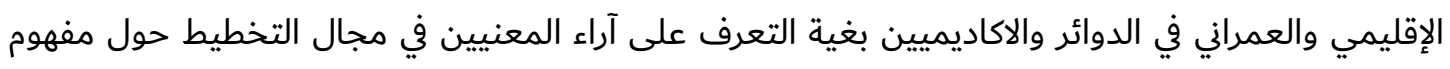

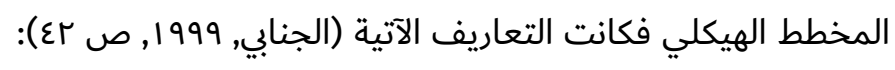

ا. المخطط الهيكلي هو مخطط عمراني على مستوى المحافظة الواحدة بحدودها الإدارية يتحدد بموجبه

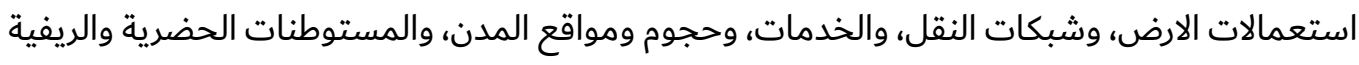
ضمن إطار المؤشرات التنموية الواردة.

r. ((أسلوب، أو طريقة تبنى بواسطتها، أو مخطط يتعامل مع منطقة النفود المؤشرة على المدينة ونشاطها الاقتصادية والعمراني (و عد حلقة وصل بين التصميم الأساس للمدينة والمخطط الإقليمي)،

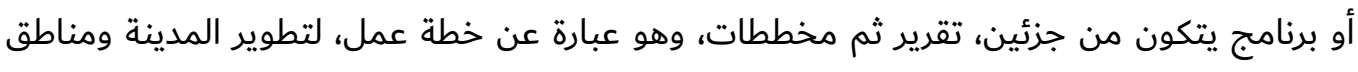


التأثير المباشر حولها، لتحقيق مجموعة أهداف يصفها المخطط، ويتم الاتفاق عليها وتنسيقها من الجهات ذات العلاقة وتنفذ بمراحل)).

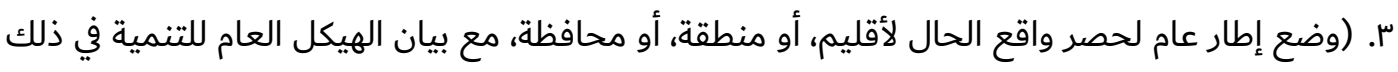

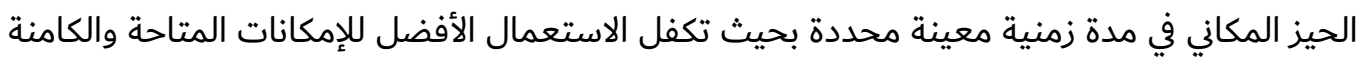
مع تحديد الاستعمالات المطلوبة والمستلزمات الضرورية الأخرى، لتحقيق التنمية لذلك الحيز المكاني). ع. على مستوى الاقليم هو الخريطة التي يبين عليها الاستغلال الأمثل لاستعمالات الأرض، والموارد الطبيعية، والتوزيع التراتبي، والمواقع الصناعية والسكنية، ومواقع المواصلات وشبكاتها. 0. ومن التعاريف المطروحة فقد وجد أن اكثر التعريف واقعية ونضوجا من حيث المحتوى التطبيقي هو

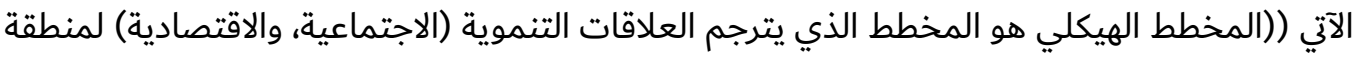

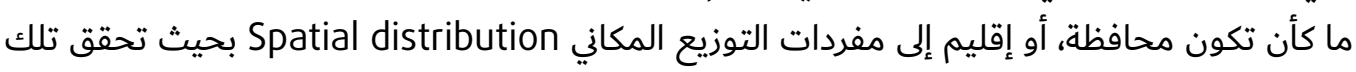
العلاقات التنموية الأهداف المطلوبة، ويكون التوزيع المكاني عنصرا مهما، لتحقيق لتلك الأهداف))

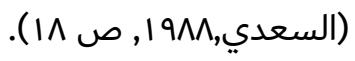

ومن هذه التعاريف يتضح عدم وجود تعريف واضح، أو مقبول يمكن ان يتم الاتفاق عليه للأسباب

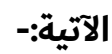

ا. عدم وجود تعريف قانوني، أو تشريعي في العراق. r. غموض مفهوم المخطط الهيكلي في العراق من جهة، وفي قوانين وأنظمة الدول المتطورة نتيجة لتبدلها المستمر من جهة أخرى. r. أ اختلاف الخلفيات الإكاديمية والخبرة العلمية للمخططين. أخيراً توصل الباحث إلى قناعة تامة بأن التعريف الآتي يمكن أن يكون أقرب التعاريف لمفهوم التصاميم الهيكلية من وجهة نظرهم التي تم طرحها تشريعيا وأكاديميا. (المخطط الهيكلي هو خطة عمل تنطوي على وثيقتين الأولى مكتوبة، لشرح الأفكار الرئيسة والأهداف

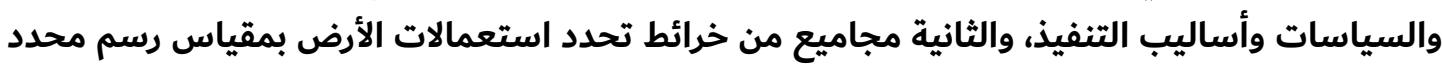

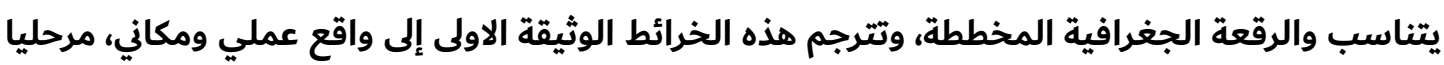

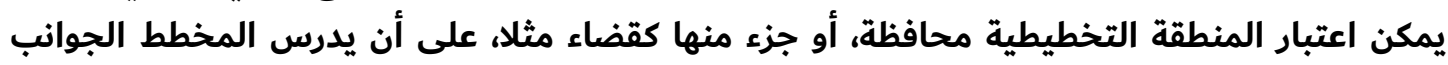

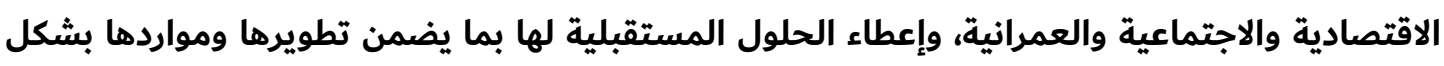

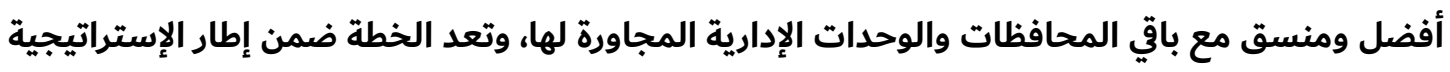
الاقليمية المعدة على وفق منظور الخطة الوطنية للتنمية في العراق)).

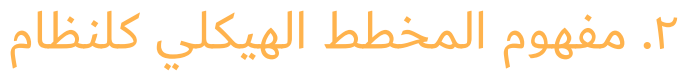

إن المخططات الهيكلية يمثل نظاماً (System) اجتماعياً واقتصادي وعمرانياً متكاملاً لمنطقة محددة يتم فيه

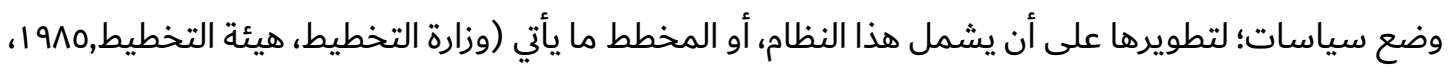




$$
\begin{aligned}
& \text { أ- توزيع السكان وعلاقات الترابطات بين تجمعاته. } \\
& \text { ب- تحديد أنماط استعمال الأراضي، وتطويرها للمنطقة المذكورة. } \\
& \text { ت- شبكة المواصلات، والنقل، والخدمات. }
\end{aligned}
$$

تلغطية هذه الأطروحات الثلاث بشكل شامل فأن المنطق يفرض دراسة للموضوعات المختلفة التي يمكن

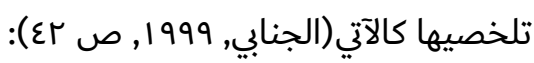

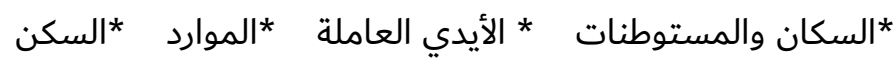

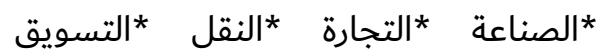

$$
\begin{aligned}
& \text { *التعليم *الخدمات الاجتماعية *الترفية والراحة *الحفاظ على البيئة }
\end{aligned}
$$

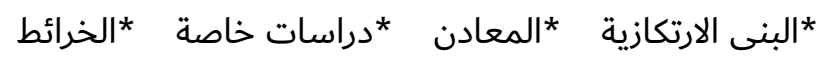

إن اعتماد هذا المستوى من التخطيط يمكن ان يعمل على خلق الترابط بين العوامل المختلفة التي تؤثر

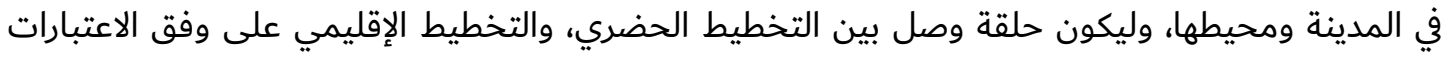

أ- تخطيط استعمالات الأرض لرقعة جغرافية اكبر من المدينة، وأصغر من الأقاليم (محافظة). ب- التوزيع المكاني للأنشطة والفعاليات التي تضمها منطقة الدراسة من (صناعة، وزراعة، وخدمات). ت- تحديد حجوم المستقرات البشرية، واتجاهات نموها العمراني، والمحددات التي توجه تلك الاتجاهات. ث- شبكة البنى والخدمات الارتكازية (طرق، ومواصلات، وكهر باء......الخ). وعلى وفق ما تقدم واستنادا إلى إطار التشريعي الذي اوجد هذا المستوى من التخطيط العمراني فأن مفهوم الخطة الهيكلية في العراق ينطوي على الاعتبارات الآتية: أ- أهداف واستراتيجيات مكانية بديلة، وأساليب تنفيذها. ب- خرائط لاستعمالات الأرض تترجم الأهداف والاستراتيجيات المكانية المعتمدة.

وهذا يعني أن الخطة الهيكلية عبارة عن... خطة لاستعمالات الأرض على غرار التصاميم الأساسية

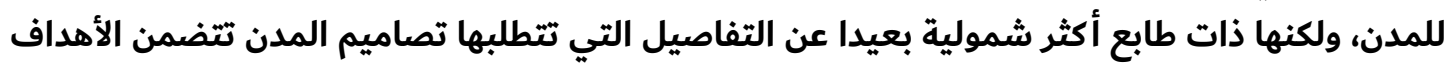

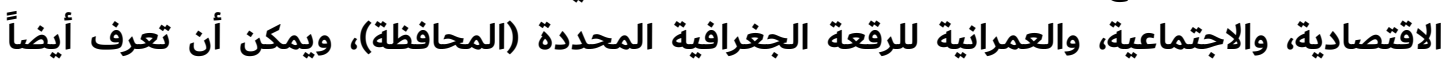

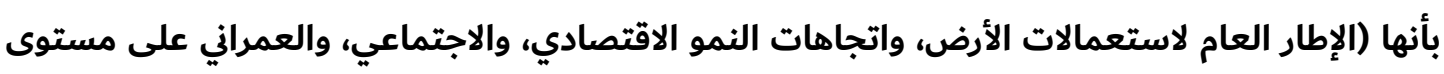

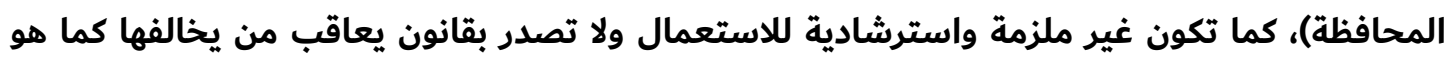

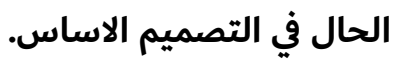

\section{ّ. المخطط الهيكلي والتنمية المحلية}

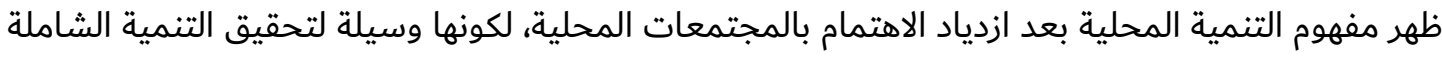

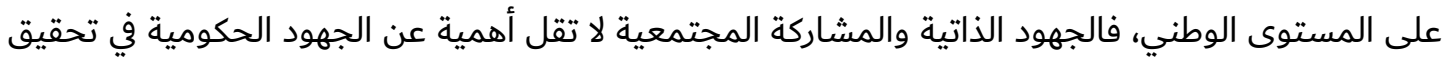


التنمية، عبر مساهمة السكان في وضع وتنفيذ مشروعات التنمية، مما يستوجب تضافر الجهود المحلية الذاتية والجهود الحكومية، لتحسين نوعية الحياة الاقتصادية، والاجتماعية، والثقافية، والحضارية للمجتمعات المحلية، وإدماجها في التنمية الوطنية. ويقوم مفهوم التنمية المحلية على عنصرين رئيسين هما:

• المشاركة المجتمعية في جهود التنمية المحلية، والتي تقود إلى مشاركة السكان عن طريق الهيئات

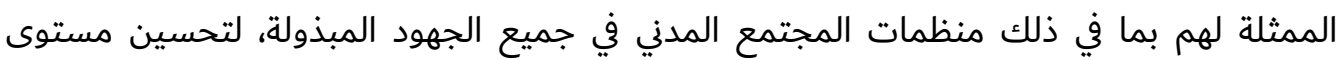
معيشتهم، ونوعية الحياة التي يعشونها معتمدين على مبادرتهم الذاتية. • توفير الخدمات ومشروعات التنمية المحلية المختلفة بأسلوب يشجع الاعتماد على النفس والمشاركة

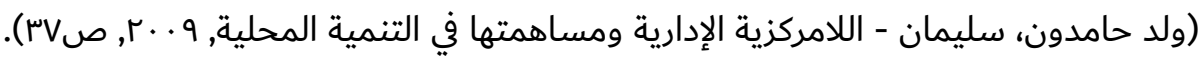

ومن ثم فمن الضروري أن تكون أنشطة التنمية المحلية والتي تتفاعل مع المواطنين بشكل مباشر أشرا ويومي جزءاً عضوياً جوهرياً في خطة التنمية الوطنية, بما يمكنهم من جني ثمار التمار التنمية الوطنية أولاًا بأول, ولتزداد قناعتهم بما تفرضه عليهم التنمية من أعباء فيشاركون فيها برضاء وقناعة تؤمن استدامة هذية هذه التهار التنمية

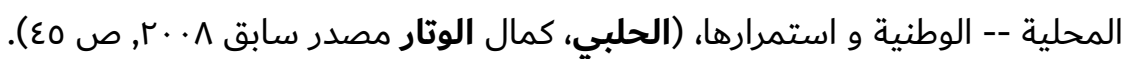
ولتتحقق التنمية بالمشاركة, فلا مناص من توفير أكبر قدر ممكن من اللامركزية في تخطيط وتنفيذ التحاليه

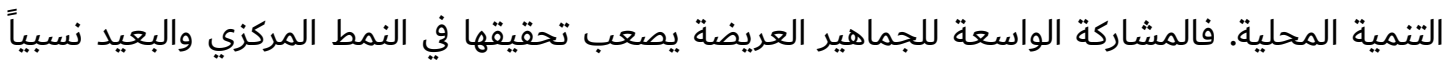
عن التلامس المباشر مع المواطنين في القرى والمدن. إن ما تملكه التنمية من أهداف وإبعاد تتجسد في حيز مكاني هو المحليات، بمعنى آخر، إن وجه التهات التداخل

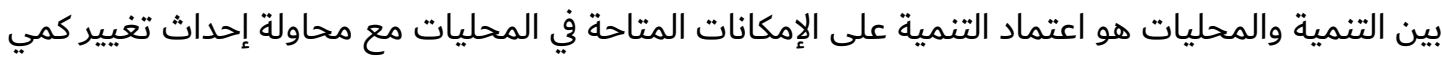

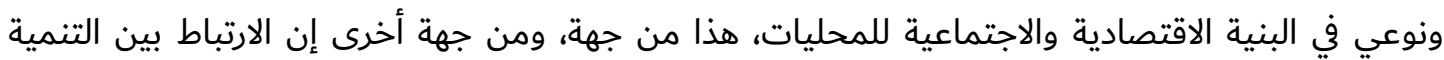

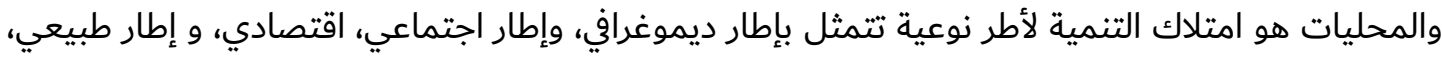
هذه الأطر تتواجد ضمن حيز مكاني تتفاعل فيما بينها، مما تعطي خصائص وصفات خاصة خاصة قد تكون عمرانية،

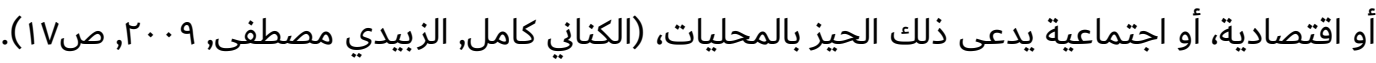
إن بلورة وتوضيح هذه العلاقة الاعتمادية المتبادلة بين تحقيق التنمية وإمكانات المحليات يتم عبر تبني آليات تخطيطية مناسبة تسهم في الاستغلال الأفضل للإمكانات التنموية للمحليات.

\section{ب-1. آليات التنمية المحلية}

التخطيط المحلي يربط بين التنمية الاقتصادية، والتنمية المكانية، ويضمن التوازن المكاني -- الوظيفي، ويؤدي

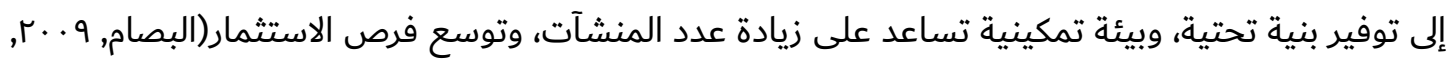

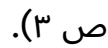

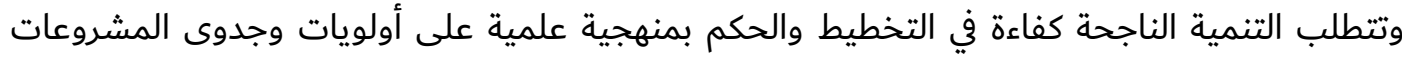

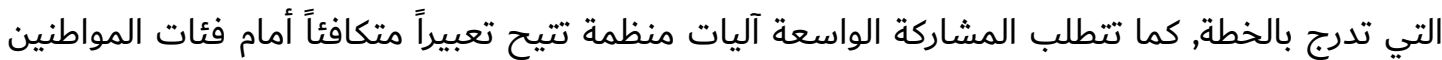

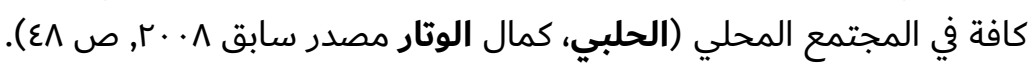

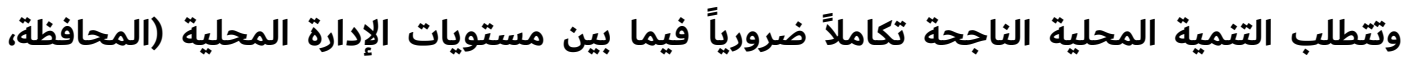
والمدينة، والبلدة، والقرية، و البلدية), وتكاملاً آخر فيما بين القطاعات التية التي تتولى فيمات الدولة مركزياً مسؤوليتها. 
وكذلك تكاملاً في الجهود التي ستبذل من جانب الدولة من ناحية، وتلك التي سيقوم بها القطاع الخاص

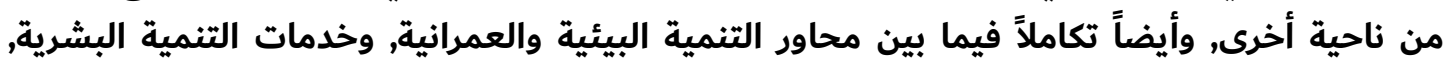

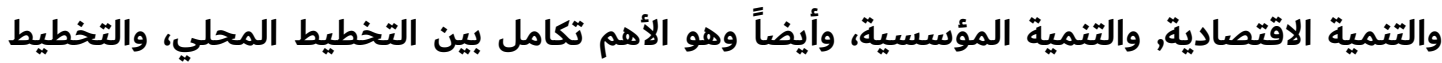

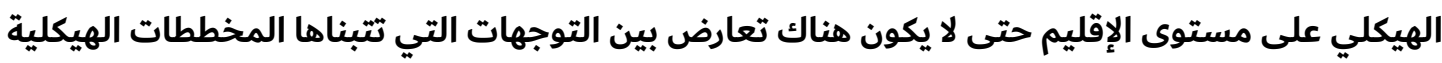

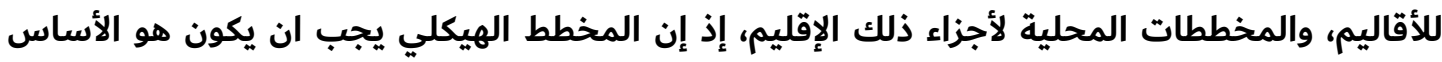

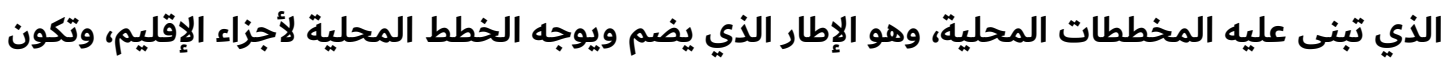

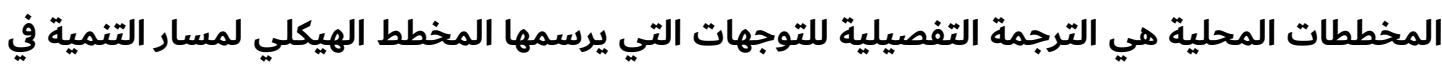

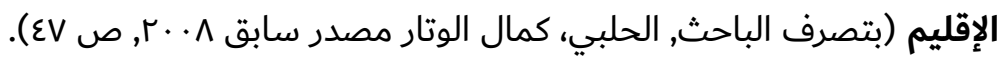

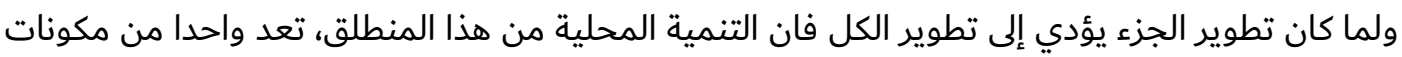
عملية التنمية الكلية, ومن ثم فان إذا تحققت التنمية في أقاليم الدولة، أو في مناطقها, فأن المحصلة المانة النهائية هي تحقق التنمية الكلية في هذه الدولة. ومن ثم فإن أربعة عناصر رئيسة تحكم إستراتيجية التنمية المحلية في الخطة المحلية وهي: التكاملية،

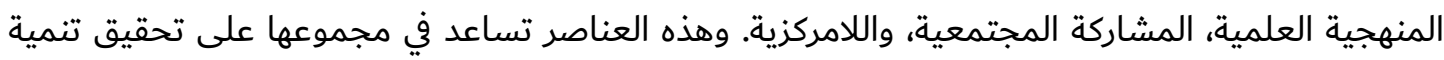

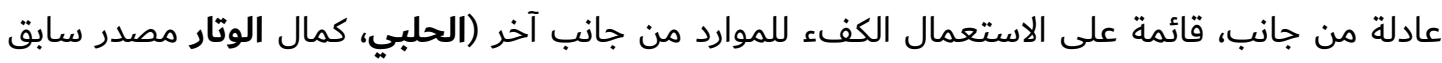

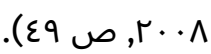

الخطط المحلية هي من المهام الإلزامية للدولة إذ أن خطة التنمية على المستوى الوطني تؤكد على ضرورة

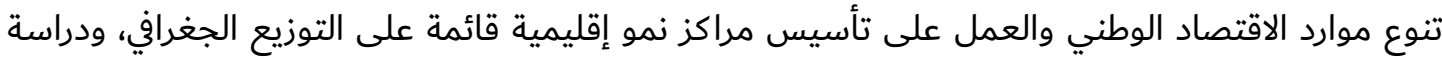

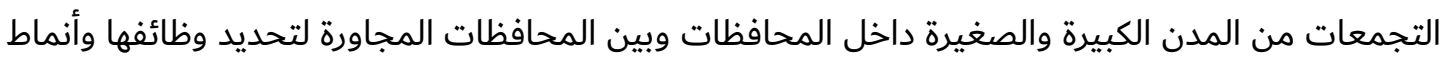
إنتاجها الرئيسية، ومن ثم تخصيص الاستثمارات العامة في إقامة البنى التحتية والفنية والاجتماعية (البصام,

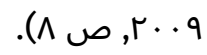

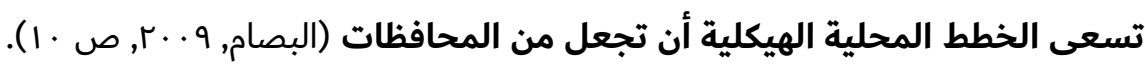

• أكثر إنتاجية: مدعومة بقوة عمل ذات كفاءة عالية وبمستوى من التحديث المؤسسي للمنشآت

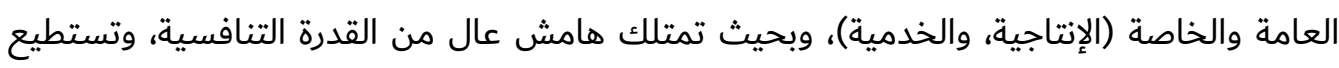

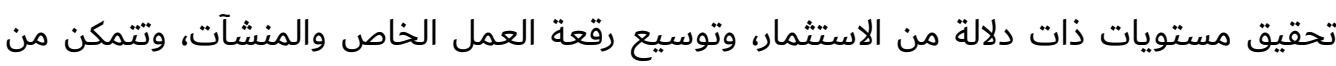

$$
\text { تطوير مستوى المهارات. }
$$

• أماكن لائقة للعيش: في ظل نوعية متميزة من التنمية الحضرية، والتخطيط المكاني، والبيئي، ومن الخدمات الاجتماعية، والثقافية، وأماكن الترويح التي تشجع المائهة المواطنين والمستثمرين على الاستقرار

$$
\text { والعمل. }
$$

\section{• مراعية للتوازن والعدل في التوزيع، وإيلاء المناطق الريفية والنائية حقها من التنمية.} • ذات اقتصاد مرن ومتنوع، وبحيث أن المستثمرين والمحدثين يستجيبون للتغير، ويحافظون على إلى هامش التنافسية للمنتج المحلي.

• ذات قاعدة معرفية ملائمة، وبمعنى زيادة مستوى التحصيل العلمي بين المواطنين المحليين، والتمتع بمستوى مهارات وقدرات مطلوبة لسوق العمل مع حس قوية معات بالأداء المتميز.

• ذات قدرة مؤسسية متطورة قائمة على الأداء الوظيفي والمهني والتقني العالي، وعلى ثقافة

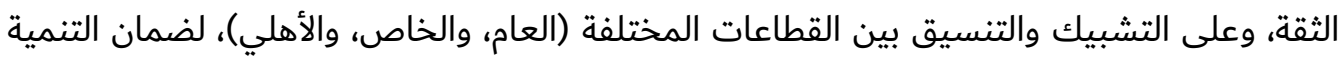


• ذات بيئة صحية، وبحيث يتمكن المواطنين من التمتع بالمنافع المتأتية من التطوير الاقتصادي المحلي.

إن تحقيق هذه الاهداف يتم عبر الترابط والتكامل والتنسيق بين الخطط المحلية، والمخططات الهيكلية

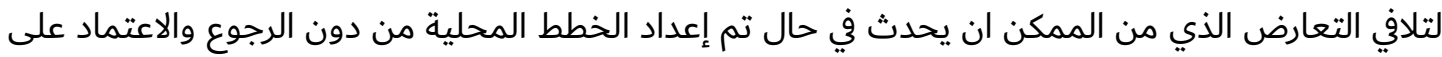
المخططات الهيكلية كخطوة اساسية وجوهرية، لتحقيق تنمية ناحجة متوازنة على مستوى الاقليم، ومن ثم على المستوى الوطني، إذ إن المخططات الهيكلية توافر رؤية واضحة لما يجب ان يكون عليه الاقليم على نلى وفق إستراتيجية منطقية ومتسلسلة تقود إلى تحقيق الأهداف والغايات المنشودة، لتحقيق تنمية ناجحة ومتوازنة في حال التزام الخطط المحلية بهذه الإستراتيجية وتبنيها وترجمتها على أرض الونة الواقع. إن إبراز أهمية التخطيط المكاني مقارنة بالتخطيط القطاعي عن طريق المخططات الهيكلية، يعد وسيلة ناجعة يتم عن طريقها تحويل الأهداف القطاعية إلى إطار عام لإستراتيجية تنمية محلية تسمح بتحقيق

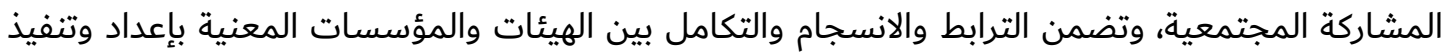

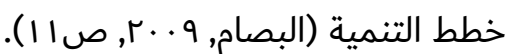

\section{ع. التخطيط الهيكلي في ظل اللامركزية}

تعرف اللامركزية الإدارية بأنها"أي فعل تقوم الحكومة عبره بنقل السلطة والمسؤولية رسميا إلى فاعلين

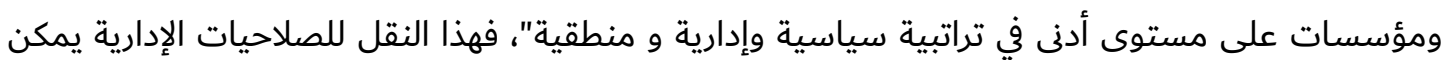

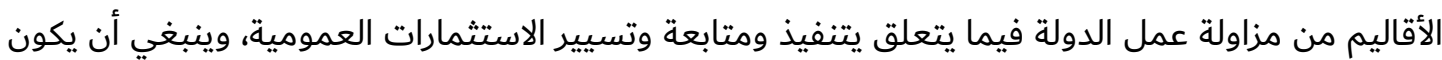
تحويل السلطات إلى الأقاليم مصاحبا بتوفير الوسائل المالية الضرورية للتنمية الإقليمية اللامركزية.

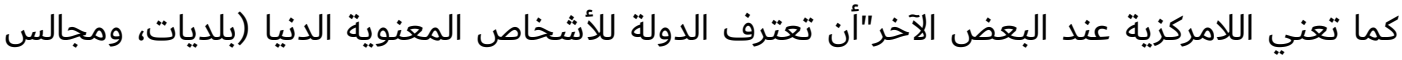
محلية، ومؤسسات عمومية) بنوع من الاستقلالية في تسيير شؤونها الداخلية، لكن دائما تحت إشراف ومراقبة

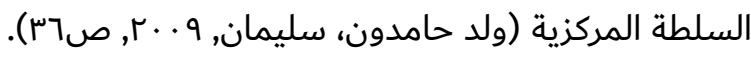
إن واحداً من أهم الدوافع لدى كثير من دول العالم لتبني اللامركزية هو ازدهار وتنمية المجتمعات المحلية.

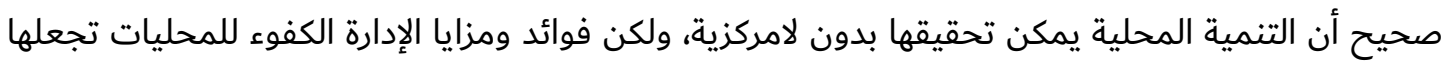

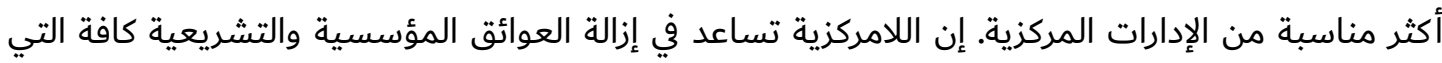

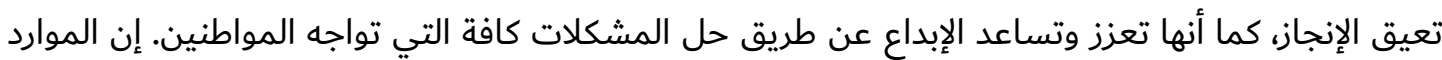

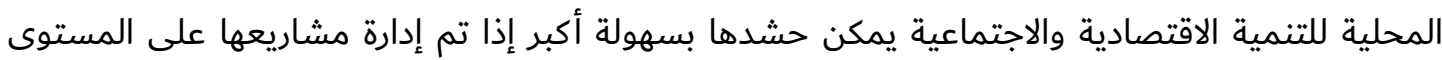

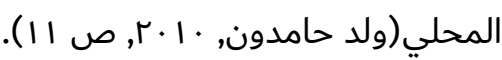

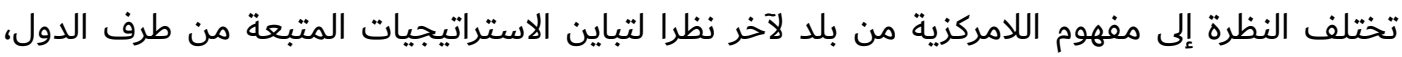

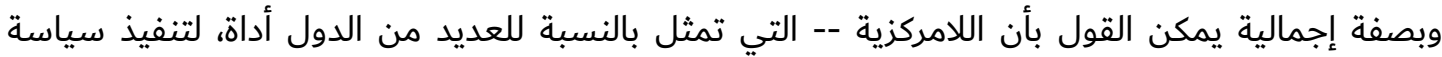

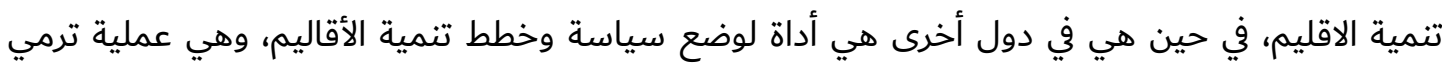

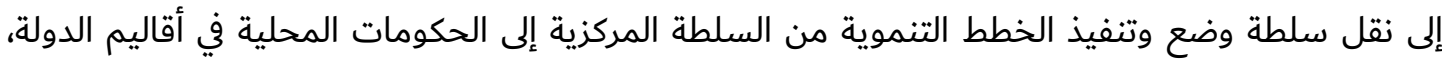

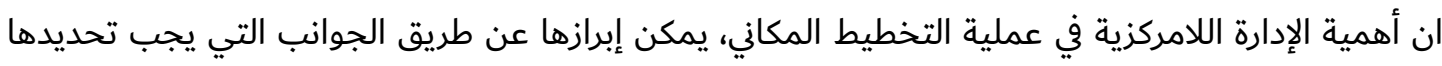

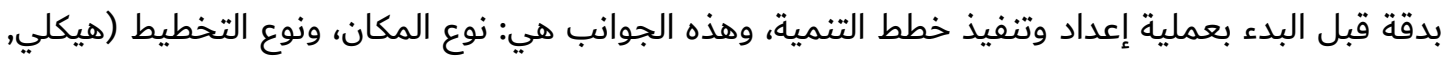

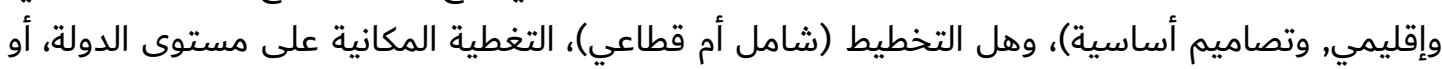

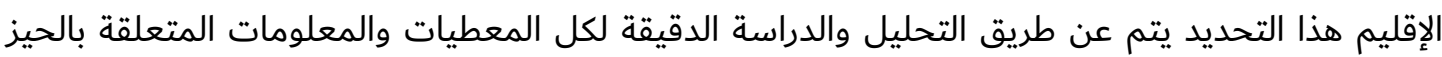


المكاني المستهدف بعملية التخطيط، لتحديد الإمكانات والمحددات لعملية التنمية، مدى إمكانية استغلال هذه الإمكانات الاستغلال الأفضل، والتغلب على المعوقات، لتحديد مستوى التنمية المطلوب تحقيقها،

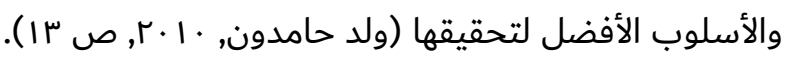
عملية التخطيط الهيكلي في ظل اللامركزية الإدارية تعني تفعيل المشاركة المجتمعية، و دور المجموعات

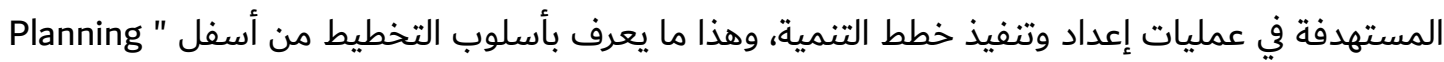
below from above"، from "Planning

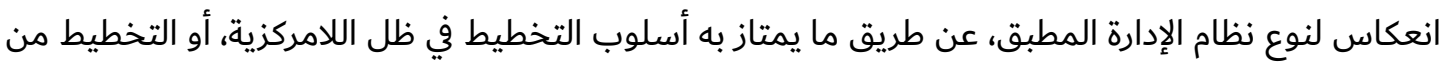

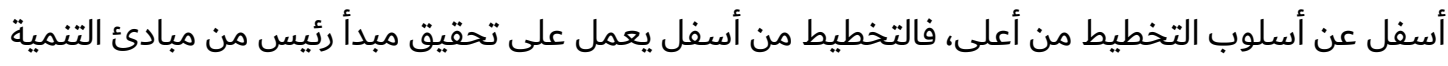

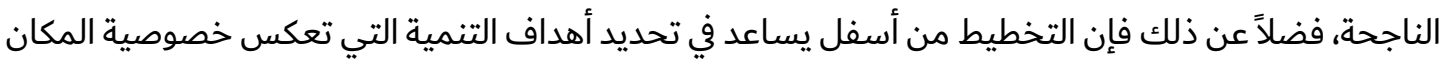

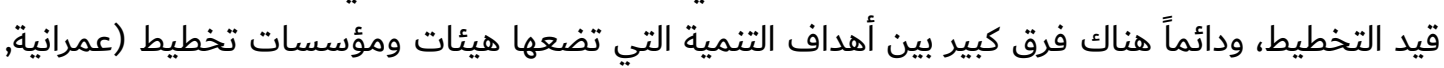

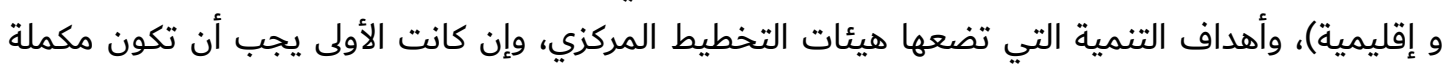

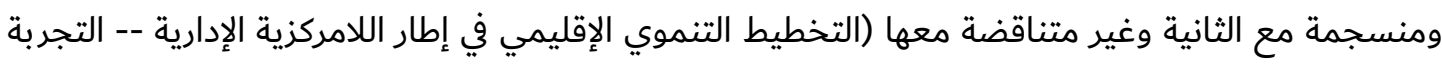

الأردنية -- (بتصرف من الباحث)، الانترنت، uqu.edu.sa/majalat/humanities/2vol14/b3.htm).

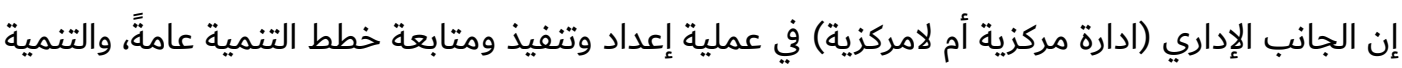

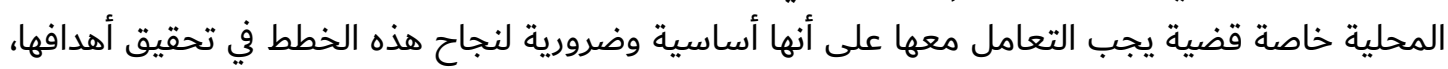

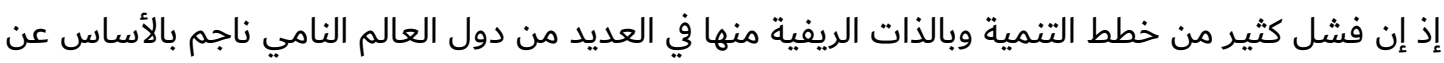

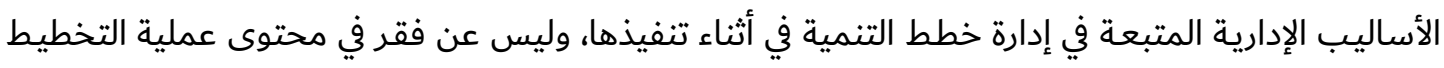

إن عملية التخطيط الهيكلي ظل اللامركزية الإدارية تعني التخطيط بالمكان، وليس تخطيط للمكان كما

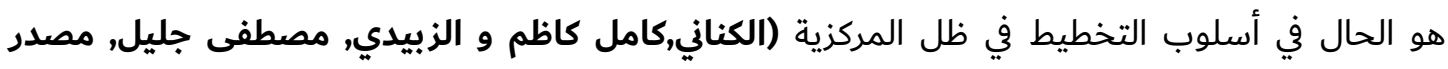

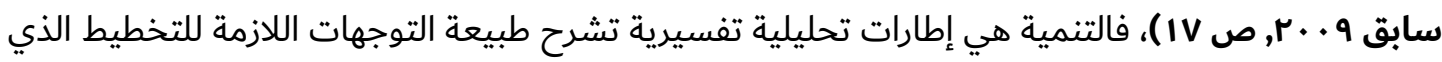

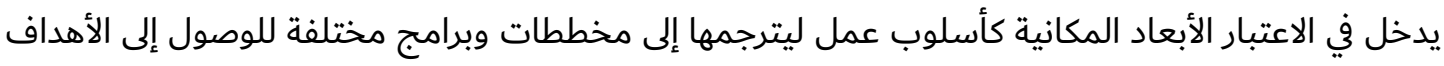
المرجوة.لذا لا بد من وضع أسس رؤية حديثة متوافقة مع المتطلبات والمعاد المعيات المات الحالية الماتية والمستقبلية لتقسيم

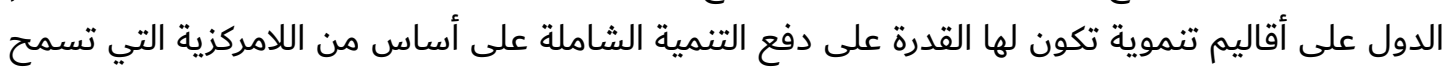

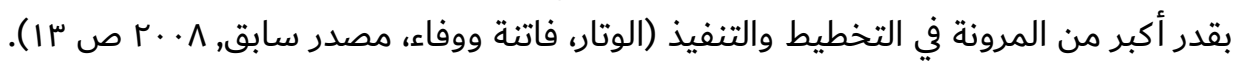

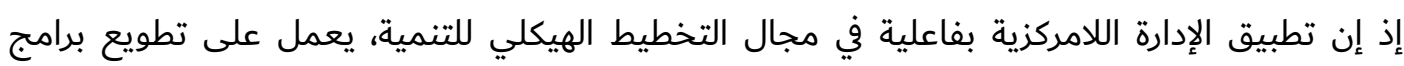

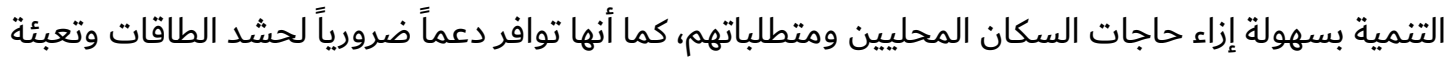

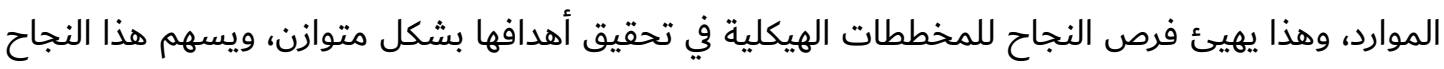

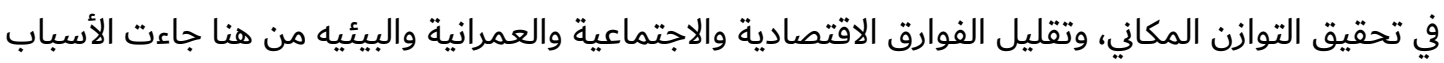

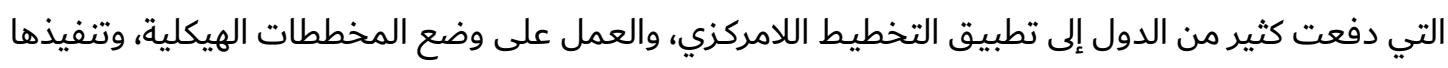
في ظل اللامركزيه، وهذه الأسباب هي (التخطيط التنموي الإقليمي في إطار اللامركزية الإدارية, التجربة الألئ الأردنية,

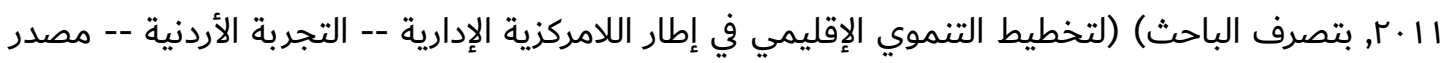
سابق (بتصرف من الباحث)): (1)

• يعمل التخطيط الهيكلي اللامركزي على إيجاد توزيع عادل نسبياً لسلطة صنع القرار والاستثمارات

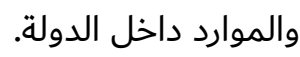


• تعني لامركزية التخطيط تنازل هيئات التخطيط المركزية عن جزء من صلاحيتها لصالح هيئات تخطيط الصيات محلية، هذه الهيئات التي تتعايش مع مشكلات السكان التان المحلييين بشكل مستمر وتدرك أسبابها

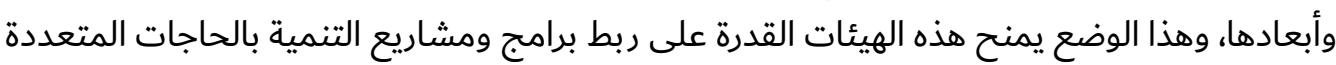

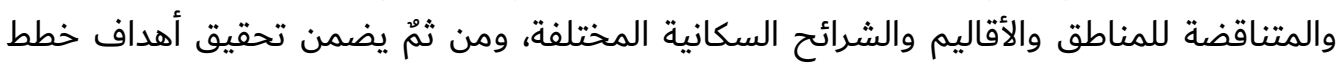
التنمية الوطنية بصورة فاعلة وإيجابية. • يُسهم في إيجاد الاتصال المباشر والمستمر بين هيئات التخطيط والسكان، وهذا يُمكّن القائمين

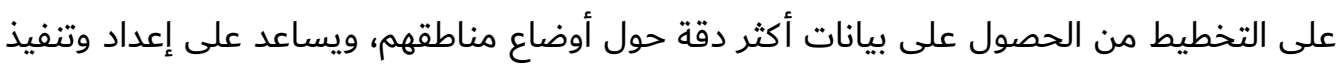
مخططات هيكلية تنموية واقعية وفعالة ومؤثرة. • تسمح لامركزية التخطيط بوصول الموارد والاستثمارات إلى جميع مناطق وأقاليم الدولة، وهذا يقلل من حدة الفوارق الاقتصادية والاجتماعية. • تعزز لامركزية التخطيط من فاعلية هيئات التخطيط المركزية، إذ تخلصها من العديد من المهمات

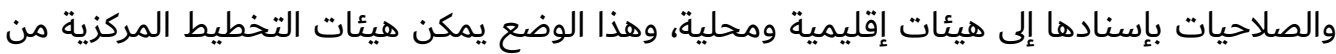
أخذ الوقت الكافي في الإشراف بشكل فعلي وعملي على متابعة خطط التنمية المختلفة. • تتطلب لامركزية التخطيط إيجاد هيئات تخطيطية, وهذا بدوره يمكّن من متابعة ومراقبة أفضل للمشاريع التنموية، ويعمل على تحقيق أهدافها. ولكي يتم إيجاد مخططات هيكلية لامركزية فاعل ومؤثر، فإنه لا بد من توافر شروط عدة هي: • توافر الإرادة السياسية عند الحكومة المركزية من أجل التخلي عن جزء من صلاحياتها التخطيطية

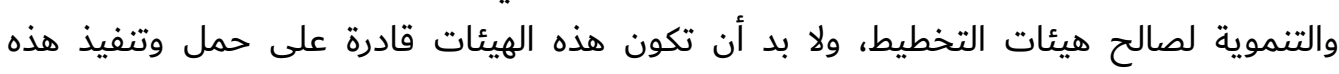
المسؤوليات الجديدة بشكل جيد وفعّال. • تطبيق المخططات الهيكلية اللامركزية الشامل، بمعنى أن منح الإدارات في الاقاليم صلاحيات الإدارة

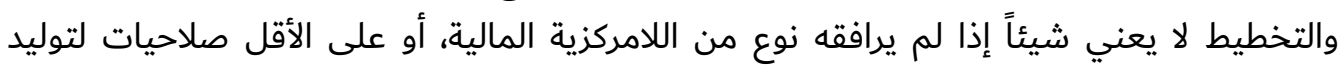

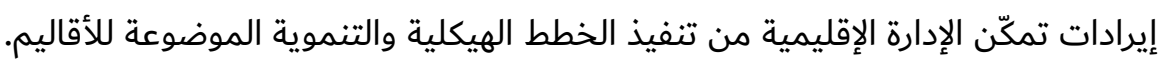
• ضرورة وجود دور واضح ومحدد في الإدارة الإقليمية للهيئات والجمعيات الأهلية وغير الحكومية. • ضرورة بناء وعي وثقافة سياسية لدى سكان الأقاليم من الحكومة المركزية عن مفهوم وأهمية وأهداف الإدارة اللامركزية.

• تزويد هيئات التخطيط بحاجاتها من البنى التحتية والكفاءات التي تمكنها من إنجاز مهماتها بكفاءة. من جهة أخرى بما أن اللامركزية هي الحالة، أو الوضع الذي يعطى فيه حق المشاركة في اتخاذ القرار

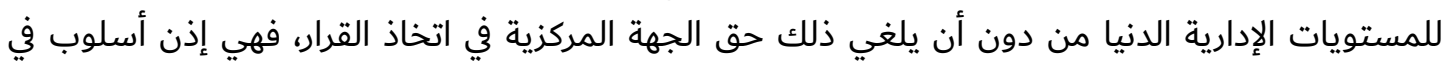

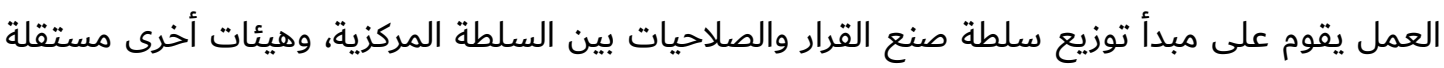

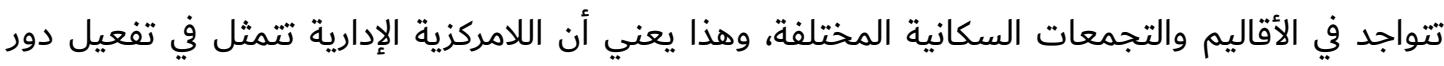

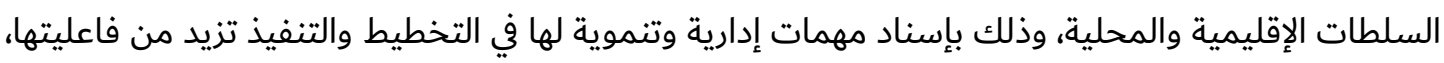
وتعزز دورها في تحمل مسؤولياتها وصلاحياتها بالشكل الذي يعمل على دمج السكان إلىان المحلية واليين في عمليات

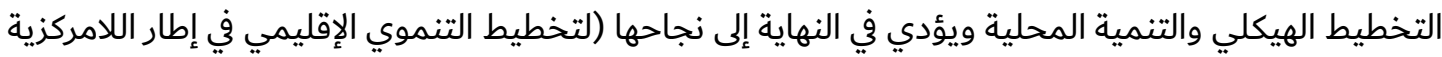
الإدارية -- التجربة الأردنية -- مصدر سابق (بتصرف من الباحث)). 
إذن التخطيط اللامركزية هو أداة لتخطيط وتنفيذ المخططات الهيكلية الناجحة والملبية للحاجات التنموية للأقاليم بمعنى ان المخططات الهيكلية الموضوعة والمنفذة في ظل التخطيط والإدارة اللامركزية ستكون

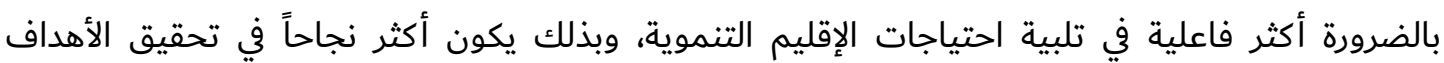

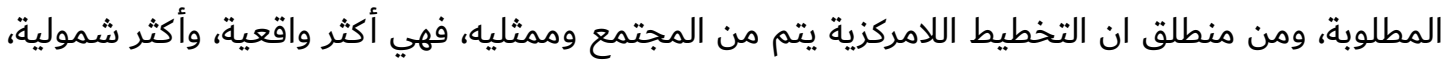

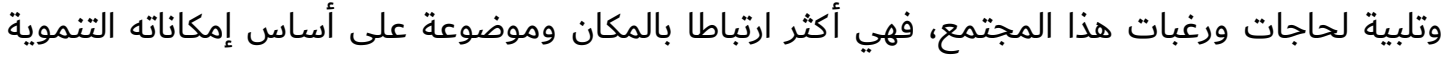

وللتوضيح اكثر ينظر الشكل (1).

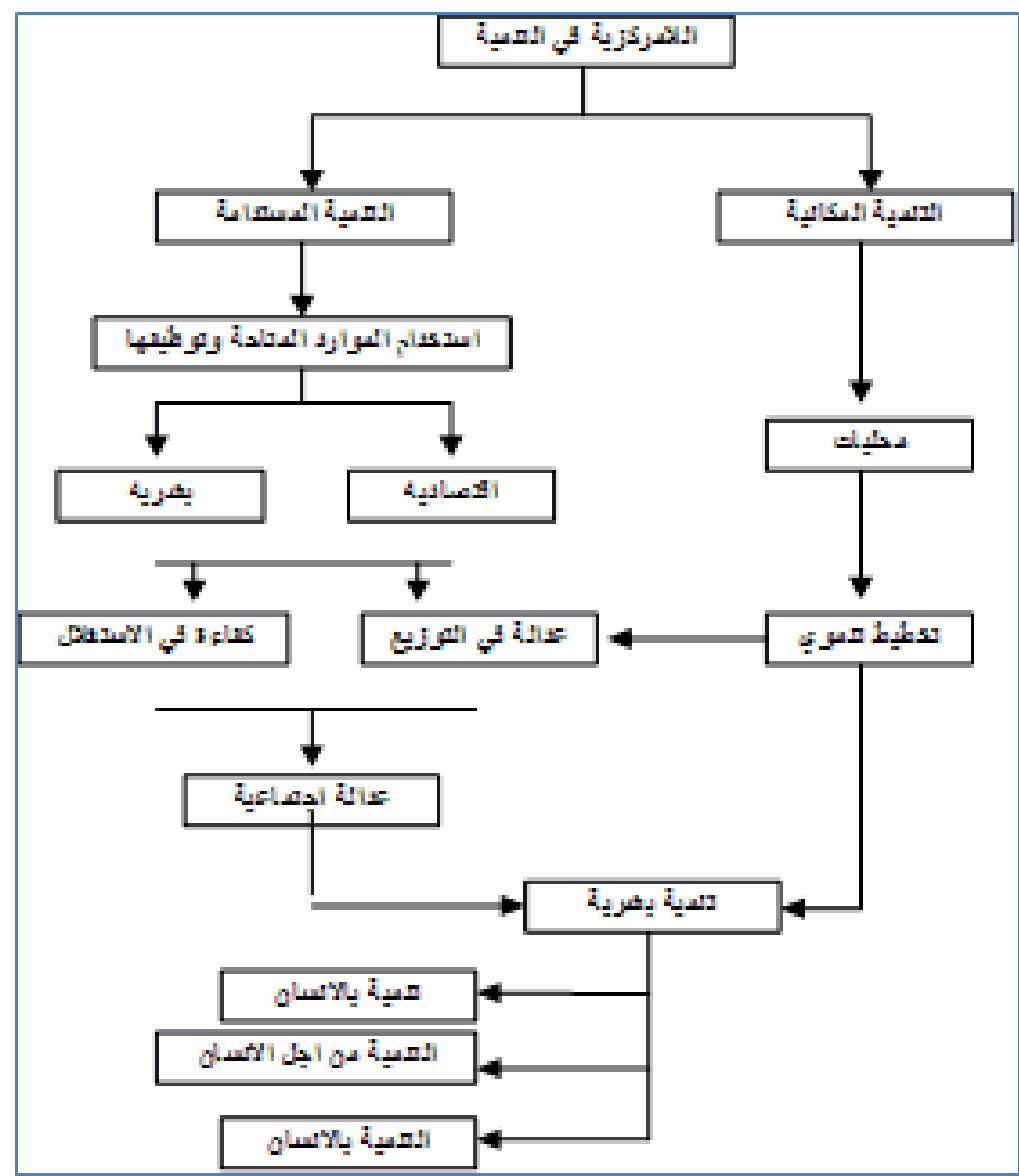

شكل ا: اللامركزية في التنمية. (المصدر/. الكناني، و صبري، اللامركزية وإدارة المجتمعات المحلية، دراسة في التخطيط

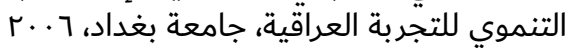

ا. رؤية التطوير تتلخص اهميتها هي في التغيير الجذري الذي تحدثه الخطة الهيكلية للمكان r. تعزيز حيوية ونمو مراطز المدن، وتحقيق الاستدامة فيها عن طريق تنظيم النمو المتوازن وإدارة الموارد المتاحة والكامنة لخلق ظهير قاعل للمدن. "ז. رفع كفاءة استغلال الموارد غير القابلة للتعويض مثل الارض. ع. عكس الانخفاض في عدد السكان عن طريق وقف الهجرة الخارجية. 
o. تفعيل التراتب الهرمي للمستقرات وتحقيق الجانب التفاعلي الوظيفي بينها. 7. بناء الرؤية والرسالة ووضع المنظور والحدود والغايات للخطط التفصيلية المحلية لاستعمالات الأرض والتصاميم الاساسية.

\section{ا. إعداد المخططات الأساسية على وفق الخطة الهيكلية.}

r. إعداد دليل إرشادي إضافي للمساعدة في تنفيذ التنمية على وفق الخطوط العريضة للمخطط الهيكلي ץ. تحديد أوجه النقص والقصور في شبكات المرافق الاجتماعية والخدمات الفنية، وتحديد مناطق التوسع المعات العمراني المستقبلية والعمل على تغطيتها وفقا للمراحل متتابعة

ع. إيجاد رؤية واضحة تسهل مهام إدارة المدينة.

[1] الحلبي، كمال -- الوتار، محمد، التنمية المستدامة مدخل للحفاظ على البيئة العمرانية إعداد - المبادرات

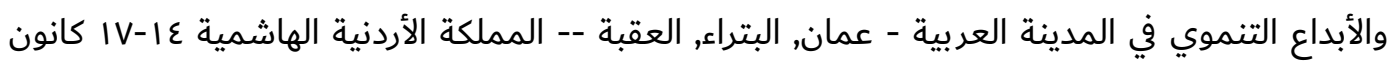

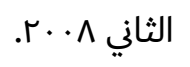

[r] السعدي، فؤاد كامل حسون، تحديد المساحات اللازمة للنشاط الصناعي ضمن اطار متطلبات اعداد الخطة الهيكلية، رسالة ماجستير مقدمة الى المعهد العالي للتخطيط الحضري والاقليمي /جامعة بغداد،

[ [ب] الكناني, كامل كاظم و الزبيدي, مصطفى جليل ابراهيم - آليات اعداد وتنفيذ المشاريع الاستثمارية في

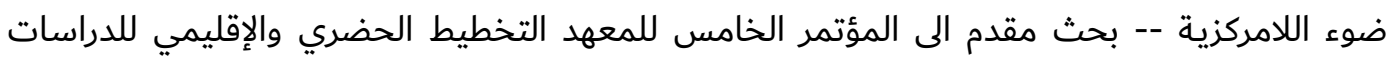

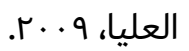
[ع] الوتار فاتنة ووفاء، الملامح التخطيطية لتحقيق آفاق التنمية المستدامة /المبادرات والأبداع التنموي في

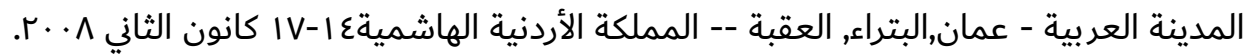
[0] وزارة التخطيط، هيئة التخطيط الاقليمي، الضوابط اللازمة لوضع خطة هيكلية ناجحة، اعداد مجموعة من الباحثين، 1919.

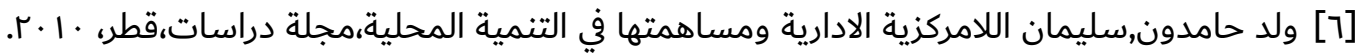

[7] Constantine D. Skordoulis and Eugenia Arvanitis, Space Conceptualisation in the Context of Postmodernity: Theorizing Spatial Representation, The International JOURNAL of INTERDISCIPLINARY SOCIAL SCIENCES, Volume 3, Number 6, 2008

[8] Dr Katrina Navickas, history, geography and social movements, Spatial theory, cultural geography, and the 'spatial turn', September 30, 2011, History and Today

[9] The Ministry of Hosing \& local Govermentm, Iraq, Baghdad, 1965. 


\section{References}

[1] H. Kamal, W. Mohamed, Sustainable Development: An Approach to Preserve the Urban Environment, (Jordan, 2008).

[2] S. Fouad, Determining the areas required for industrial activity within the framework of the requirements of preparing the structural plan, master research, (Baghdad, 1988).

[3] K. Kamel, Z. Mustafa, Mechanisms for the preparation and implementation of investment projects in the light of decentralization, 5th conference for urban and regional center for postgraduate, (2009).

[4] W. Fatina, Planning features for sustainable development prospects, Initiatives and development creativity in the Arab city, (Jordan, 2008).

[5] Ministry of Planning, Controls for a successful structural plan, (1985).

[6] S. Hamdon, Administrative decentralization and its contribution to local development, (Qatar, 2010).

[7] C. D. Skordoulis, E. Arvanitis, Space conceptualization in the context of postmodernity: theorizing spatial representation, (IJISS, Volume 3, Number 6, 2008).

[8] N. Katrina, History, geography and social movements, Spatial theory, cultural geography, and the 'spatial turn', (2011).

[9] The Ministry of Hosing \& local Government, Iraq, Baghdad, (1965). 